\title{
Diccionario de términos ambientales. Antecedentes, propuesta terminográfica y estudio terminológico
}

\author{
Aurora M. Camacho Barreiro \\ Instituto de Literatura y Lingüística (La Habana)
}

El Instituto de Literatura y Lingüística -a través de su sección de Lexicografía Especializada Monolingüe- emprendió a comienzos de 1996 la elaboración de un diccionario de términos ambientales a propuesta del Centro de Información, Gestión y Educación Ambiental (CIGEA).

Previamente, en el verano del mismo año, se reunieron en La Habana los ministros de Medio Ambiente de Iberoamérica para discutir y acordar estrategias de trabajo comunes. Los especialistas cubanos habían reparado ya en el hecho de que en Cuba no existía ningún repertorio terminográfico en esta materia. De igual forma, habían percibido la necesidad de unificar la terminología al uso en América Latina y el Caribe. Por lo tanto, fueron los propios especialistas quienes se plantearon la urgencia de un proyecto como el emprendido posteriormente y dieron los pasos necesarios para encaminar tales propósitos.

En su carácter esencialmente interdisciplinario, la problemática del medio ambiente resulta compleja y de difícil delimitación conceptual (arbórea) o temática. Dada la síntesis original de varias disciplinas que confluyen en el ámbito la recopilación de la información general fue decisiva.

En este artículo, nos proponemos dar cuenta de la investigación realizada. Por esta razón, se impone un breve análisis sobre los antecedentes y el estado actual de la temática. Además, se comentará acerca de la 
estructuración en campos o áreas objeto de estudio, sobre la conformación del fichero de vaciado y el diseño y aplicación de nuestro modelo de ficha terminológica; ambas, etapas esenciales en la elaboración del diccionario. Por último, y en consonancia con los estudios terminológicos de mayor actualidad, se intentará una aproximación al vocabulario medioambiental como tecnolecto o lenguaje de especialidad y se señalarán algunas de sus regularidades lexicogenésicas.

Según se pudo constatar, son escasas las obras terminográficas de esta temática elaboradas en lengua española y escasas las surgidas en $\mathrm{Cuba}^{1}$. Los repertorios que se consultaron -el Glosario de términos sobre medio ambiente (1989), de Vicente Sánchez y Beatriz Guiza y el Diccionario de medio ambiente (1994), de Olga Roger y Ana Andrés, editados en Chile y en España, respectivamente- no tienen una fundamentación metodológica explícita y la selección de los términos resulta casi arbitraria, sobre todo si se tiene en consideración que la terminografía más moderna se erige sobre sólidos presupuestos teóricos y se inclina más por la estructuración sistemática o por temas y no por la alfabética. En estas obras alternan los términos simples y los complejos con idéntico tratamiento terminográfico, las abreviaturas y los nombres de convenios, eventos, etc.

En estos repertorios la selección responde a criterios muy generales que resienten el producto final, pues el espectro parece ser tan amplio que resta exhaustividad. Como ha expresado R. Alpízar al referirse al asunto "mientras más se extienda la visión horizontal, menos se podrá profundizar en la visión vertical" (1992: 2).

Otra peculiaridad advertida es la vacilación en lo relacionado con la información terminográfica y la definición propiamente dicha. Los autores mencionados siguen al menos tres modelos o patrones de explicación especializada:

1 Se conoce que la Facultad de Lenguas Extranjeras de La Universidad de la Habana emprendió también la elaboración de un Diccionario multilingüe de medio ambiente, del cual ya se han obtenido algunos resultados parciales. 
- la elaboración de la definición a partir de los datos obtenidos en las textos de especialidad ${ }^{2}$,

- la utilización de definiciones elaboradas por otros autores, diferenciadas por el empleo de comillas, negritas u otras marcas tipográficas,

- la inserción de definiciones extraídas de diccionarios generales de la lengua ${ }^{3}$.

Los diccionarios, vocabularios o glosarios especializados son, en esencia, obras de referencia, por lo tanto no pueden ser la base para la selección de los términos.

Asimismo, en el universo bibliográfico del ámbito medioambiental son muy numerosas las propuestas que se acercan al subsistema léxico de una determinada esfera. Esta perspectiva posibilita una mirada vertical al fenómeno estudiado y, en definitiva, una profundización mayor. El Diccionario de ecología (s.a), el Glosario de términos básicos sobre toxicología ambiental (1984) y el Diccionario de términos biológicos (1989), son algunos ejemplos de esta modalidad.

Sin embargo, no debe ignorarse que algunos profesionales elaboran listados de términos usados en los textos especializados, que resultan aclaratorios para el lego. En este sentido, M. Célio Conceição advierte:

[...] que los propios especialistas y/o técnicos de los más diversos dominios, por regla general, brindan todo el apoyo necesario [...] o elaboran ellos mismos miniglosarios dispuestos en el interior de las

2 Por ejemplo, los creadores del Glosario de términos de medio ambiente (1989) confiesan en el acápite de los planteamientos metodológicos que "la selección de las definiciones fue hecha de acuerdo con el marco conceptual establecido, y cuando el equipo de investigadores no consideró satisfactorias las definiciones encontradas en los textos [...], los especialistas elaboraron nuevas definiciones [...]" (cursiva A.C.B., 1989: 13).

3 El Diccionario de medio ambiente (1994) recoge definiciones ya aparecidas en el Diccionario académico (1992). Solo un ejemplo basta para ilustrar el empleo de definiciones semejantes: "turba f. Combustible fósil formado de residuos vegetales acumulados en sitios pantanosos...". 
obras de especialidad, los cuales constituyen la llamada terminología escondida (traducción y cursiva A.C.B., 1996: 26).

En el caso del medio ambiente también existe la tendencia de elaborar proyectos de esta naturaleza, en particular si se trata de profundizar en áreas o subáreas específicas, es decir, si prevalece la mirada vertical a los fenómenos. Esta práctica de la llamada "hidden terminology" (terminología escondida) es de gran utilidad, pues el especialista, de acuerdo con su experiencia, selecciona la terminología de acuerdo con su criterio profesional y ofrece al usuario su propia definición.

En Cuba, por otra parte, se han dado pasos decisivos en la protección legal del medio ambiente. En nuestra pesquisa se tuvo en cuenta la Ley N”33 de 1981 “De Protección del Medio Ambiente y del Uso Racional de los Recursos Naturales"; la Ley No 81 de 1997 así como otras legislaciones ambientales vigentes.

En el caso de la Ley 33 encontramos definiciones dentro de los artículos, precedidas por la expresión "se entiende por" y otras que aparecen enlistadas en orden alfabético. La ley aprobada en 1997 contiene un capítulo con una serie de vocablos bajo la denominación de "Conceptos básicos". Las leyes, además de constituir documentos especializados de necesaria consulta en tanto registran la terminología al uso entre los especialistas contienen, como pudimos confirmar, conceptos esenciales. En este sentido, conviene apuntar que la inserción de definiciones en los textos legales ha generado no pocas polémicas, pero al parecer en Cuba se sigue esta tendencia.

Asimismo, fueron consultadas las Normas para la proteccción del medio ambiente (1987) - conjunto de documentos técnico-normalizativos (DTN) que seguían las normas internacionales del CAME (Consejo de Ayuda Mutua Económica), de acuerdo con los criterios de normalización vigentes en los antiguos países socialistas. Estas normas referidas al medio ambiente contienen términos y definiciones de diversas áreas temáticas, tales como bosques, paisajes, suelos, tierra, atmósfera, entre otras. Con la desaparición del campo socialista, perdieron vigencia en Cuba las normas CAME y las correspondientes al dominio medioambiental no son una excepción. En la actualidad todos 
los documentos normativos están siendo revisados para adaptarlos a los lineamientos ISO (Organización Internacional de Estandarización).

La investigación nos condujo, asimismo, al trabajo directo con los textos representativos -obras técnicas o científicas, manuales, informes, ponencias, catálogos, etc., elaborados por autores cubanos-, pues son precisamente éstos los documentos primarios para la selección de la terminología. Son, en el reconocido criterio de M. T.Cabré "el nido de la terminología en su forma oral o escrita" $(1996)^{4}$. El terminólogo, en definitiva, debe extraer de esos documentos las unidades o términos que integrarán los diccionarios, que son productos caracterizados por sus fines, por sus destinatarios, por sus dimensiones y por su tema u objeto de estudio.

El carácter especializado de un determinado texto no está condicionado solamente por la restricción del tema seleccionado, sino también por "[...] las circunstancias específicas en que dichos textos se producen o por las finalidades que deben cumplir" (Cabré 1993: 225-226).

El Diccionario de términos ambientales (2000), es monolingüe, pues tiene como lengua de trabajo al español; responde a un orden alfabético, pues se ha preferido ofrecer información sobre la concatenación conceptual sólo a través de códigos y notificaciones dentro de la macroestructura del diccionario, teniendo en cuenta que el orden sistemático es más usado en repertorios de campos pequeños; es definitorio, porque se recoge la definición especializada y es descriptivo , $_{2}$ porque se propone registrar el léxico usado por los especialistas de las disciplinas del medio ambiente previamente seleccionadas. Sin embargo, no se excluye la prescripción, ya que el uso de un término cualquiera se legitima con su entrada en el diccionario.

En este último aspecto, debe recordarse -como advierte R. Alpízarque descriptivismo y normativismo se complemetan en una relación

4 Esta cita se extrajo de los apuntes tomados durante el Curso Internacional para Investigadores en Terminología, impartido por la Dra. María Teresa Cabré en la sede habanera de Unión Latina, en 1996. 
dialéctica (1992: 2), pues al describir un estado del tecnoléxico se está colaborando con la fijación de un determinado uso.

Entre otros objetivos, el Diccionario... se propone contribuir a paliar la carencia de productos terminográficos de esta naturaleza en el mundo hispánico. La obra, publicada en Cuba sin fines lucrativos en su primera edición de 3000 ejemplares, está dirigida fundamentalmente a los estudiantes de las disciplinas afines y fue controlada por lingüistas y asesorada en sus diversas etapas por los especialistas del ámbito. El repertorio consta de 415 unidades terminológicas.

Para facilitar el acceso a la información que brinda el diccionario se estableció un sistema de remisiones internas que indican los términos relacionados (TR: sinónimos, equivalentes, antónimos, etc.). Asimismo, empleamos una marca de observación (Obs.) con el propósito de destacar algunas informaciones de interés registrados en los textos de la especialidad, la existencia de siglas y el uso en Iberoamérica de voces equivalentes.

La obra presenta, además, una abundante bibliografía y una exhaustiva relación de los principales convenios y tratados internacionales a los que Cuba está suscrita así como de los más relevantes organismos e instituciones nacionales e internacionales en el dominio del medio ambiente.

Para M. T. Cabré los lexicógrafos emplean pautas expresivas a mitad de camino entre la definición lingüística y la terminológica, que incluyen con notable frecuencia características enciclopédicas (1993: 209). En nuestro caso, recurrimos por su precisión a la definición terminológica.

Se hizo necesaria, entonces, la discusión con los especialistas para arribar a la necesaria delimitación de conceptos claves en la temática medioambiental y la correspondiente concatenación jerárquica. Con ello, llegamos a la estructuración del árbol temático. Las disciplinas que se entrelazan y algunas áreas en las que las fronteras son borrosas, obligan al personal especializado y al terminólogo a precisiones imprescindibles. 
Sin lugar a dudas, la relevancia de los estudios y aplicaciones terminográficas y terminológicas es considerable en un mundo en el que imperan las nuevas tecnologías y las ciencias se subdividen y especializan incesantemente en nuevas áreas de estudio. Por lo tanto, la elaboración de terminologías, así como su normalización, es una premisa del desarrollo.

Como pasos preliminares para la elección y análisis de las áreas temáticas, se realizó conjuntamente con los especialistas la exploración y el análisis conceptual del ámbito de la especialidad en su espectro más amplio. Con ello, se daban los primeros pasos para precisar las ramas y subramas de la estructura arbórea y para llegar a fijar la posición de cada elemento en el sistema de nociones del medio ambiente a tener en consideración.

Las propuestas elaboradas se discutieron con los especialistas de diversos centros afines a la problemática medioambiental, entre ellos el CIGEA, el Instituto de Ecología y Sistemática (IES), el Centro Nacional de Áreas Protegidas (CENAP) y el Instituto de Geografía Tropical (IGT). Finalmente se conformó el siguiente árbol temático, simplificado o abreviado en este artículo en su ramas y subramas principales.

\section{ÁRBOL TEMÁTICO DEL DICCIONARIO DE TÉRMINOS}
AMBIENTALES
I. Recursos
1.1. Recursos edáficos
1.2. Recursos energéticos
1.3. Recursos industriales y minerales
1.4. Recursos hídricos
1.5. Recursos forestales
1.6. Recursos pesqueros
1.7. Conservación - Rehabilitación
1.8. Manejo - Gestión - Ordenación
2. Agricultura
3. Impacto ambiental
3.1. Evaluación del impacto ambiental 
4. Contaminación y Residuos

4.1. Contaminación

4.2. Contaminantes

4.3. Residuos

4.4. Tratamiento - Utilización

5. Política ambiental

5.1. Evaluación ambiental

5.2. Gestión ambiental

5.3. Derecho ambiental

5.4. Inspección ambiental

5.5. Educación ambiental

5.6. Planificación ambiental

5.7. Investigación ambiental

5.8. Información ambiental

5.9. Ética ambiental

6. Ecosistemas

6.1. Ecosistemas terrestres

6.2. Ecosistemas costeros e insulares

6.3. Ecosistemas marinos

6.4. Ecosistemas de agua dulce

6.5. Ecosistemas de ciénaga

6.6. Ecosistemas de montaña

6.7. Ecosistemas forestales

7. Medio ambiente - Desarrollo

7.1. Agricultura sostenible

7.2. Tecnologías limpias

7.3. Reciclaje

7.4. Economía ambiental

7.5. Industria - Medio ambiente

7.6. Turismo - Medio Ambiente

Esta estructura arbórea nos permitió precisar el tema y su alcance, así como elaborar las definiciones de los términos bajo presupuestos lógicos y sistemáticos.

De igual manera, resultó muy provechosa la consulta de los Tesau- 
ros de términos ambientales (1990 y 1997), elaborados por el Sistema Internacional de Documentación Ambiental (INFOTERRA) y por el Programa de las Naciones Unidas para el Medio Ambiente (PNUMA) respectivamente. A través de los descriptores y los no descriptores, así como de las notas de alcance, el usuario tiene acceso a un sistema jerarquizado de relaciones entre los términos enlistados, que definen su contenido semántico. Por esta razón, además de ser un instrumento de catalogación y clasificación de documentos de gran utilidad, un tesauro constituye un material imprescindible en la delimitación nocional de un ámbito dado.

Vencidas las etapas anteriores estuvimos en condiciones de conformar una lista preliminar con la terminología de la especialidad. Dicha relación de términos -que contenía alrededor de 700 unidades, entre términos propiamente dichos y sintagmas terminológicos- circuló entre los especialistas y retornó a nuestro equipo de trabajo acompañada de sugerencias y enmiendas.

Entre las propuestas recibidas pueden mencionarse las siguientes:

- eliminación de algunos términos por ser específicos de otras disciplinas y no ser relevantes dentro del ámbito,

- sustitución de las palabras de uso en el contexto iberoamericano por las empleadas en el discurso especializado por los profesionales cubanos,

- exclusión de la simbología química o utilización de ésta sólo en aquellos casos en que se correspondan con la estructuración conceptual del ámbito,

- utilización en singular de los términos,

- inclusión de las denominaciones de organismos, organizaciones e instituciones nacionales e internacionales, de acuerdo con el grado de vinculación con la problemática,

- consideración de incluir o no las denominaciones de convenios, tratados, acuerdos, etc.

Las últimas cuatro sugerencias merecen algún comentario. La no- 
menclatura química -en su forma desarrollada- se ha incluido solo en el caso en que su relevancia para el tema sea obvia y en tal sentido, aparecen con remisiones internas, es decir, se registra la simbología y su correspondiente explicación. Por ejemplo, el compuesto químico CFC o clorofluorocarbonos es un contaminante atmosférico de gran alcance y como nuestro árbol conceptual contiene la contaminación como concepto básico, debe aparecer esta denominación.

En el caso del uso en singular o plural se ha optado por la primera forma. Por otra parte, sobre el cuarto y quinto aspecto se acordó preparar un anexo contentivo de dichas denominaciones, por ser muy numerosas y no corresponder con nuestra perspectiva metodológica su incorporación entre los artículos terminográficos, a diferencia de la mayor parte de los repertorios consultados que sí lo registran en la macroestructura.

Según la opinión de A. Fedor de Diego (1995: 59), un término puede ser una palabra, una abreviación, una notación, un acrónimo, un número, una letra, o un símbolo gráfico. Partiendo de esta consideración, que de manera general comparten otros autores, incluimos en nuestro diccionario los términos o unidades terminológicas simples que forman parte del ámbito especializado, así como las unidades complejas que, como se demostrará en el epígrafe previsto, se distinguen por el grado de precisión que proporcionan al dominio del tecnolecto.

En la conformación del fichero de vaciado de la terminología medioambiental se partió de la ubicación de los términos en los textos representativos y de la delimitación del segmento contextual que los representa.

La ficha de trabajo para el vaciado de la información quedó diseñada de la siguiente forma:

\begin{tabular}{|l|l|}
\hline Entrada & Cod. Categoría gramatical \\
\hline Contexto & Fuente \\
\hline Referencia & \\
\hline
\end{tabular}


La entrada incluye el término en su forma singular con la marca correspondiente a su categoría gramatical, en el caso de la unidad terminológica simple.

En el espacio del contenido se indica la caracterización de este, es decir, si se trata de una ficha de definición, de contexto, de fuente o de otro tipo.

Las fuentes deben reunir ciertos requisitos, entre ellos: ser materiales actualizados, difundidos entre los especialistas, de notable relevancia técnica o científica; deben estar redactados en la lengua de trabajo del repertorio terminológico en elaboración (monolingüe, en este caso ) $\mathrm{y}$ aparecer en forma escrita, aunque no se descarta el discurso especializado oral. En las referencias de las fuentes aparecen el nombre del autor del texto, el título, el año de edición y la página.

Tal como se recomienda en la bibliografía de más reciente resonancia, se decidió preparar tantas fichas de vaciado como usos diferentes encontráramos en el documento fuente, pues de esta manera el fichero, en su condición de base de datos, complacerá las necesidades del terminólogo y redundará en un mejor producto terminográfico.

En definitiva, la utilidad de cualquier diccionario, especializado o de la lengua general, estará determinada por la relación entre las necesidades del usuario o destinatario y el producto terminográfico o lexicográfico mismo. En esa medida, la elaboración de la terminología, la selección de los términos de uso general entre los especialistas así como el manejo de los textos fueron etapas determinantes en la investigación.

En el caso del contexto es preciso delimitarlo en su forma más extensa, a partir del estudio del texto especializado para que, una vez contextualizado el término-entrada, el usuario de la base de datos tenga una mayor información sobre su uso. Los contextos se dividen en testimoniales, que ilustran el uso; definitorios, que aportan información sobre el contenido y metalingüísticos, que ofrecen elementos sobre los términos como unidades del sistema de la lengua. Veamos algunos ejemplos extraídos de nuestro fichero de vaciado: 


\section{a) Contextos testimoniales}

Debido a la relativa baja disponibilidad de tierras agrícolas para la producción agropecuaria que existe en Cuba, unido a su condición insular, [...], el sector agropecuario siguió la estrategia de la revolución verde, y por tanto asumió las deficiencias ecológicas del modelo citado [...] (Estudio nacional sobre la diversidad..., 1995: 28).

Se debe evitar y corregir las acciones que favorezcan la erosión, la salinización y otras formas de degradación o modificación de sus características topográficas y geomorfológicas (Ley del medio ambiente, cap. 5, Proyecto, 1996).

\section{b) Contextos definitorios}

La erosión es el conjunto de fenómenos exógenos que contribuyen al desgaste del modelado terrestre (Revista El agua, $\mathrm{n}^{\circ} 32$, 1988).

La Reserva de la Biosfera se define como zonas protegidas de ecosistemas costeros y terrestres representativos, importantes tanto para la conservación como la obtención de conocimientos prácticos y valores humanos que puedan contribuir a un desarrollo sostenible (Atlas del medio ambiente del Caribe, 1995).

\section{c) Contextos metalingüísticos}

Una de las principales amenazas de los bosques europeos actuales son las lluvias ácidas, provocadas por la presencia de compuestos de azufre y de nitrógreno en la atmósfera, [...] que al ser arrastrados por la lluvia le confieren a ésta un carácter ácido (Respuesta educativa a la crisis ambiental, 1991).

El tema de la contaminación transfronteriza ha sido centro del debate internacional y no ha encontrado el respaldo que por su importancia era de esperar; aunque por la posición y las peculiaridades del régimen climático, la región puede verse afectada en determinadas situaciones por las contaminaciones generadas en otras latitudes (Atlas del medio ambiente del Caribe, 1995). 
Nuestra ficha terminológica fue elaborada a partir del modelo que aparece en la Metodologia del Treball Terminologic (1990). De acuerdo con los presupuestos teórico-prácticos que se recogen en ese volumen se consideraron todos los datos posibles sobre los términos a incluir finalmente en el diccionario, pues el fichero terminológico es también un instrumento de trabajo de extraordinaria utilidad para el equipo terminográfico. Como afirmara E. Faulstich en las Actas del III Simposio Iberoamericano de Terminología celebrado en la Rioja en $1992^{6}$ :

(la ficha) mantiene el control de la calidad de la información, durante la elaboración de la microestructura discursiva, más también porque su secuencia funciona como un hilo conductor de la organización macroestructural de la obra (traducción de A.C.B., 1997: 131).

Nuestro modelo de ficha terminológica quedó diseñado así:

\begin{tabular}{|l|l|l|}
\hline 1. Unidad terminológica & 2. Área temática & 3. Fuente \\
\hline & 4. Categoría gramatical & \\
\hline 5. Definición & \multicolumn{2}{|l|}{} \\
\hline 6. Contexto & \multicolumn{2}{|l|}{} \\
\hline 7. Términos relacionados & 8. Índice de confiabilidad & 9. Tipo de palabra \\
\hline 10. Observaciones & 11. Fecha de elaboración & 12. Nombre del autor \\
\hline
\end{tabular}

El tratamiento de la definición terminográfica exige especial atención, pues el terminógrafo no debe alterar las nociones y el sistema de conceptos que encuentra en la literatura especializada. La definición, como expresión compleja equivalente semánticamente al término que define, debe respetar una serie de convenciones generales referentes a la

5 Didáctico volumen traducido al catalán por M. T. Cabré a partir del original Metodologie de la recherche terminologique (1987), de P. Auger y L. Rousseau.

6 Para mayor información se sugiere la consulta de la comunicación presentada por E. Faulstich al III Simposio Iberoamericano de Terminología, publicada en 1997. 
adecuación a los principios lingüísticos y semánticos, a su adecuación específica a un dominio temático y a su expresión (Cabré, 1993: 312).

De la información contenida en las fichas se incluirá en nuestro diccionario la información de acuerdo con la siguiente ecuación:

\section{término de entrada = categoría gramatical \pm variante(s) + defini- ción \pm Observación + área temática +término relacionado \pm remisión}

Veamos algunos ejemplos ilustrativos:

área protegida loc Parte determinada del territorio nacional declarada de relevancia ecológica, social e histórico-cultural para la nación. Sinón.: zona protegida. (P.A.)

compost $\mathbf{f} 1$. Abono orgánico, rico y oscuro, producto de la descomposición de desechos, que posee un contenido balanceado de nutrientes, microorganismos y minerales./ 2. Proceso de descomposición de la materia orgánica. (A)

fertilizante biológico loc Producto que contiene células vivas, que se aplica a las semillas o al suelo para mejorar el rendimiento de los cultivos. (A) TR: biofertilizante.

humedal $\mathrm{m}$ Área de marismas, pantanos, turberas, con agua estática o que fluye, fresca, salobre o salada que incluyen zonas de aguas marinas de poca profundidad. (E)

\section{ANÁLISIS TERMINOLÓGICO}

Para este análisis se ha considerado el fichero de vaciado, es decir todo el vocabulario registrado originalmente. En nuestra descripción del léxico medioambiental partimos del presupuesto de que cada lenguaje técnico es un inventario de todos los recursos lingüísticos empleados en la comunicación especializada.

Los procedimientos más utilizados para formar unidades terminológicas son los siguientes (Schmitt, 1992: 3147):

7 En su artículo "Spanisch: Fachsprachen", Christian Schmitt nos pone en contacto con los estudios más recientes sobre terminología hispánica y contribuye a la caracterización de esta disciplina. 

a) terminologización
b) formación de palabras
c) abreviación
d) préstamos

a) Se trata de una forma de ampliación del significado de una palabra, por cuanto esta se mueve del léxico general de una lengua a un ámbito especializado donde adquiere un significado nuevo sin perder ni cambiar su significado en el lenguaje común. La terminologización constituye uno de los procedimientos de mayor productividad en la formación de términos científico-técnicos, como un mecanismo que revela la permeabilidad de las fronteras entre la lengua general y la lengua especializada, así como su interacción.

En las siguientes denominaciones está presente la traslación metafórica:

cinturón verde Conjunto de parques, jardines, arbolado, que rodea a una ciudad y favorece las condiciones del clima por el intercambio entre zonas periféricas y urbanas.

cuerpo de agua Depósito natural como por ejemplo manantiales, riachuelos, etc., donde se almacena agua con diversos fines.

deuda ecológica Acumulación de efectos ambientales del pasado, en términos de disminución de los recursos naturales y deterioro del medio ambiente, que perjudicará a las generaciones futuras.

espejo de agua Área extensa cubierta de agua que se acumula en depósitos artificiales.

estrés ecológico Serie de cambios desestabilizadores del geosistema que se producen al romperse los mecanismos autorreguladores y de autocontrol.

isla de calor Zona de un territorio en la cual la temperatura del aire es mayor que en el resto de las zonas circundantes.

pastos marinos Fondo de sedimentos formado por plantas herbáceas y algas.

pulmón verde Terreno destinado a dar albergue y refugio a la flora y a la fauna.

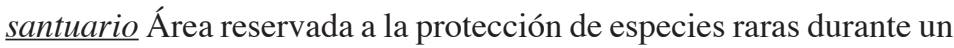
período determinado. 
No se encontraron muchos ejemplos de este tipo, pues prevalecen los tecnicismos unívocos, con un significado no traslaticio.

b) En los tecnolectos se forman palabras a través de los procedimientos propios del léxico general. La derivación y la composición son los mecanismos de mayor productividad.

Afijos más empleados

Prefijos:

$a-$ : abiótico, abiota;

acui-: acuicultivo, acuicultura;

bio-: bioabono, bioasimilación, bioacumulación, biodegradación, biodiversidad, biofertilizante, biogás, biomasa, biopesticida;

de(s)-: desalinización, descontaminación, desnitrificación;

eco-: ecoclima, ecodesarrollo, ecoingeniería, ecotecnología, ecotoxicología

re-: reforestación;

Sufijos:

-aje: alevinaje, compostaje;

-al: humedal, seibadal;

-ción: aridización, antropización, climatización, cloración, compactación, desertificación, eutroficación;

-eo: monitoreo;

-icida: agricida, algicida, bactericida, insecticida;

-idad: sostenibilidad, sustentabilidad;

-ismo: conservacionismo, ecologismo;

-ista: conservacionista, ecologista;

-ístico, a: faunístico, florístico

Composición.

Por parasíntesis.

Entre los términos formados por parasíntesis tenemos: agrosilvopastoril, agrosilvicultura, microcontaminación, hipersalinidad, fotodegradable, entre otros.

Por composición simple. 
Algunos compuestos son: autoconsumo, etnobotánica, hidrocultivo, sotobosque, siempreverde, tecnosistema, agropaisaje, agroquímica, petroquímica, piscicultura.

Puede señalarse como rasgo característico de la formación de palabras en este ámbito de especialidad la productiva derivación con morfemas cultos de origen grecolatino, tales como acui-, bio-, eco-, entre otros. En particular, son frecuentes estos dos últimos por la ligazón semántica con el dominio del medio ambiente y, además, porque permiten abreviar de acuerdo con el principio de economía lingüística-el discurso especializado. Por ejemplo, se utilizan preferentemente los términos biodiversidad y biofertilizante frente a sus parejas diversidad biológica ofertilizante biológico, respectivamente.

Por composición compleja.

Por su especificidad los términos complejos o sintagmas terminológicos merecen comentario aparte, por cuanto la delimitación de su extensión puede resultar problemática.

A juicio de M. T. Cabré:

[...] no resulta nada fácil lograr delimitar con exactitud el segmento que corresponde a un sintagma terminológico, ya que la forma de un término sintagmático puede llegar a coincidir incluso con su propia descripción [...] (1993: 177).

Definitivamente, la distinción de los términos sintagmáticos se nos presenta como una tarea de gran complejidad. Para enfrentar dicha tarea en la actualidad se perfeccionan programas, destinados a la selección, almacenamiento y procesamiento de unidades terminológicas complejas, que asisten al terminólogo. La precisión de las unidades complejas así como su elevado índice de frecuencia, constituyen elementos a tener en cuenta en su delimitación.

Los modelos estructurales más frecuentes en el tecnolecto medioambiental fueron:

I) sustantivo + adjetivo

II) sustantivo + adjetivo + adjetivo 
III) sustantivo + preposición + sustantivo

IV) sustantivo + adverbio + sustantivo

V) sustantivo + adjetivo + preposición + sustantivo + (adjetivo)

VI) sustantivo + preposición + sustantivo + adjetivo

VII) sustantivo + preposición + sustantivo + preposición + sustantivo

VIII) sustantivo + adjetivo + conjunción + sustantivo + adjetivo

IX) sustantivo + preposición + sustantivo + conjunción + sustantivo

Veamos en cada caso algunos ejemplos:

I. accidente ambiental, agricultura sostenible, agua blanda/ contaminada/ potable, área deforestada/ forestal / protegida, balance ecológico, bosque protector/ productor, bosque siempreverde, calentamiento global, calidad ambiental, cambio climático, cinturón verde, contaminación ambiental / atmosférica/ transfronteriza, control biológico, daño ambiental, delito ambiental, desarrollo sostenible/ sustentable, desastre ambiental, desechos peligrosos, dimensión ambiental, diversidad biológica, impacto ambiental, parque nacional, política ambiental, recurso renovable, reserva ecológica, tecnología limpia, uso sostenible.

II. área natural silvestre, área forestal productora/ área forestal protectora, compuestos orgánicos volátiles, desechos sólidos urbanos, efecto ambiental transfronterizo, paisaje natural antropogénico, reserva faunística manejada/ reserva florística manejada, elemento natural destacado.

III. agricultura de montaña/ de subsistencia, alternancia de cultivos, capacidad de carga, categoría de manejo, conservación in situl conservación ex situ, cuerpo de agua, espejo de agua, límite de tolerancia, ordenación de bosques, planta de tratamiento, refugio de fauna, reserva de biosfera, tratamiento de residuos.

IV. recurso no renovable.

V. control biológico de plagas, sistema sustentador de vida, área protegida de recursos manejados. 
VI. declaración de impacto ambiental, degradación de(l) medio ambiente, estándar de calidad ambiental, gases de efecto invernadero, manejo de recursos naturales, sistema de gestión ambiental, sistema de vigilancia ambiental.

VII. especie en peligro de extinción, índice de calidad de vida.

VIII. espacios terrestres y marítimos protegidos, paisajes terrestres y marinos protegidos.

IX. ecosistema de montaña y cordillera.

Como puede comprobarse, la estructura sustantivo + adjetivo -que supone un primer grado de precisión en el tecnolecto- se emplea productivamente. En el caso de los términos que han sido separados por barra sencilla (/) se trata de diferentes clases, tipos o modos de clasificación en el área o subárea especializada. Ilustra esta advertencia el caso de los sintagmas bosque protector/ bosque productor, que aluden al uso que el hombre hace de ellos y por otra parte, el bosque siemprever$d e$, que responde a una distinción de acuerdo con el ciclo vegetativo.

La formación de sintagmas terminológicos que se articulan entre sí en redes conceptuales se expresa a través de denominaciones formadas por más de dos elementos y en la medida que los compuestos se integran con nuevos elementos se alcanza mayor precisión. En este vocabulario, la frecuencia de uso de los modelos sintagmáticos sustantivo + adjetivo + adjetivo (II) y sustantivo + adjetivo + preposición + sustantivo (+ adjetivo ) (IV) señala una tendencia que se erige sobre la base del sistema conceptual de la disciplina, pues denota una mayor complejidad nocional. En tal sentido, vale tener en consideración las siguientes precisiones sobre los distintos niveles de opacidad semántica de las unidades terminológicas:

El primer grado está constituido por aquellas unidades que, si no son conocidas de antemano por el hablante, su significado no es deducible a partir de la forma. En un segundo grado hallamos los términos formados por morfemas, cuyo significado contribuye al significado del conjunto [...]. El tercer grado de opacidad está ocupado por unidades más transparentes como es el caso de los sintagmas descriptivos (Cabré 1993: 303). 
c) La presencia de algunas abreviaturas (siglas y acrónimos) en los textos representativos elaborados por los especialistas pone de manifiesto la tendencia -común en la lengua general- a la economía de recursos idiomáticos. Entre otras, encontramos las siguientes:

CFC o clorofluorocarbonos

DBO o demanda bioquímica de oxígeno

DQO o demanda química de oxígeno

EIA o evaluación de impacto ambiental

HCFC o hidroclorofluorocarbonos

También es frecuente encontrar abreviaturas de denominaciones de eventos, organizaciones e instituciones nacionales o internacionales vinculados con el medio ambiente, tales como:

CNUMAD o Conferencia de Naciones Unidas sobre Medio Ambiente y Desarrollo

WWF o Fondo Mundial para la Naturaleza (en inglés )

INFOTERRA o Sistema Internacional de Documentación Ambiental

PNUMA o Programa de las Naciones Unidas para el Medio Ambiente

SNAP o Sistema Nacional de Áreas Protegidas

La explicación de las siglas y acrónimos en los textos de los especialistas, aparecida generalmente entre paréntesis o con alguna otra marca junto a la correspondiente forma abreviada, contribuye a esclarecer el significado para el lego. La alternativa contraria, que supone la tendencia a emplear formas abreviadas sin explicación alguna, contribuye a la oscuridad del texto en la medida que resulta ininteligible para un receptor lego. Desde luego, tal condición está determinada por la clase textual y su destinatario.

d) Como sucede con otras áreas del conocimiento científico-técnico el empleo de las nuevas tecnologías provenientes de países con economías poderosas también nos hace subsidiarios de sus terminologías, fundamentalmente en inglés, francés y alemán. Esta condición de dependencia económica condiciona la penetración de voces técnicas de 
esas lenguas en el español como préstamos propiamente dichos y como calcos.

En el primer caso tenemos los términos compost, stress ecológico y smog. La primera denominación alterna en textos iberoamericanos con la voz composta $a^{8}$ que en Cuba no parece usarse. La segunda se usa indistintamente con la forma castellanizada estrés y la última, que aparece en la NC 93-02-102 / 1987 se utiliza entre los especialistas en lugar de su equivalente niebla contaminante. También encontramos algunos calcos (con adaptación fonética),entre los cuales están biodiversidad, aridización, desertificación, minimización, pesticidas ${ }^{9}$, sinergismo, sustentabilidad, sustentable, estas últimas alternan con las voces sostenibilidad y sostenible, respectivamente. Por otra parte, el tecnicismo polución se desecha de forma generalizada y en su lugar se emplea contaminación. En el caso del anglicismo monitoreo es preferido entre los especialistas frente a las formas traducidas seguimiento o vigilancia, término este último que aparece también en la citada norma y al que sigue, también entre paréntesis, el término en inglés monitoring.

Es conveniente insistir en el hecho de que los lingüistas, los terminólogos, los traductores y otros profesionales de la lengua están en el deber de velar por la salud del idioma español y de demostrar -frente a la fuerza invasora del inglés, poderoso también por razones extralingüísticas-, que nuestro idioma no tiene limitaciones de orden estructural o léxico para expresar el desarrollo científico-técnico.

Elevar el español al rango de lengua de comunicación científica -a través de la producción, normalización y difusión de terminologías-es también una contribución a la defensa de la identidad nacional.

8 En Iberoamérica tiene gran productividad este calco, pues ha generado una abundante derivación. Por ejemplo: compostaje y compostificación.

9 Del latín PESTIS, que en español se ha transformado en la denominación peste en alusión a las plagas que atacan a los cultivos. Asimismo, ha generado la derivada pestici$d a$, que se alterna con la voz plaguicida. 


\section{SOBRE LA SINONIMIA}

Por otra parte, se presentaron problemas con la selección de uno u otro término de las siguientes parejas. Los especialistas hacen uso indistintamente de ellos en correspondencia con su formación académica, la escuela o corriente de la cual es seguidor y el dominio de su propio idioma y de otras lenguas. Estos fueron algunos de los casos problémicos:

sostenibilidad-sustentabilidad

sostenible-sustentable

antrópico-antropogénico

En sentido general, se trata de voces sinónimas, pero su posible sustitución contextual debe ser precisada por el especialista. En definitiva, en terminología -entendida como disciplina lingüística- se trata de eliminar la sinonimia para acercarse a una univocidad del lenguaje científico-técnico, que es en esencia relativa, pues un término dado puede redefinirse en ámbitos de especialidad diferentes y en el seno de una especialidad determinada.

\section{A MANERA DE CONCLUSIÓN}

En la fase final de elaboración del Diccionario de términos ambientales, quedan muchos aspectos aún por comentar, pero sirvan estas páginas de preámbulo necesario para una investigación terminológica inconclusa. En este camino, una obligada parada será el estudio de los textos especializados, el "hábitat natural" de la terminología, reorientación de los estudios de especialidad en los últimos años.

\section{BIBLIOGRAFÍA}

AlPíZAR, R. (1992): “Descripción y prescripción en los diccionarios terminológicos", Anuario L/L, 23, pp. 1-12.

(1990): Traducción y terminología científica en Cuba, La Habana, Edit. Científico-Técnica.

CABré, M. T. (1993): La terminología. Teoría, metodología, aplicaciones, Barcelona, Edit. Antártida/ Empuries. 
_ (1996): "Importancia de la terminología en la fijación de la lengua: la planificación terminológica", Revista Internacional de Lingua Portuguesa, 15, pp. 9-24.

Conceição, M.C. (1996): “Terminologías em Português: uma Questão de Sobrevivência”, Revista Internacional de Lingua Portuguesa, 15, pp. 25-30.

FAULSTICH, E. (1997): "Elaboração de um glossário de termos de melhoramento genético de plantas", en Actas del III Simposio Iberoamericano de Terminología, La Rioja, 1997, pp. 129-137.

Fedor De Diego, A. (1995): Terminología. Teoría y práctica, Caracas, Edit. Universidad Simón Bolívar.

Schмiтт, Ch. (1992): "Spanisch Fachsprachen", en Lexicon der Romanistichen Lingüistik (Enciclopedia de Lingüística Romance), Tübingen, Max Niemeyer, 1992, pp. 295-327.

TERMCAT (1990): Metodologie del treball terminològic, Barcelona, Generalitat de Catalunya, Departament de Cultura.

\section{ANEXO \\ DICCIONARIO DE TÉRMINOS AMBIENTALES (LETRA A)}

A

ABIOCENO m

Componente no vivo que se encuentra en el medio ambiente

AT: RECURSOS

\section{ABIOTA f}

Conjunto de componentes carentes de vida en un ecosistema, que comprende factores climáticos, geológicos, geomorfológicos, hidrológicos, pedológicos, entre otros.

AT: ECOSISTEMAS

TR: BIOTA

ABIÓTICO (A) adj

Referido a los componentes del medio ambiente, carentes de vida.

AT: ECOSISTEMAS

TR: BIÓTICO (A)

ABONO BIOLÓGICO loc $\rightarrow$ ABONO ORGÁNICO 
ABONO NATURAL loc $\rightarrow$ ABONO ORGÁNICO

ABONO ARTIFICIAL loc $\rightarrow$ ABONO QUÍMICO

ABONO ORGÁNICO loc

Producto formado por materia orgánica de origen animal o vegetal que se emplea para fertilizar la tierra.

AT: AGRICULTURA

TR: ABONO BIOLÓGICO, ABONO NATURAL, BIOABONO

\section{ABONO QUÍMICO loc}

Producto químico que se aplica a los terrenos para mejorar o aumentar su fertilidad y para ajustar su acidez o alcalinidad.

AT: AGRICULTURA

TR: ABONO ARTIFICIAL, FERTILIZANTE

\section{ABONO VERDE loc}

Restos de cultivos que se incorporan al suelo para mejorarlo y fertilizar la tierra .

AT: AGRICULTURA

\section{ABRASIÓN f}

Desgaste de las costas por la acción de las olas del mar.

AT: RECURSOS

\section{ACIDIFICACIÓN f}

Proceso químico que se manifiesta como resultado de un incremento de la concentración de iones hidronio $(\mathrm{H}+)$ en determinados componentes del medio ambiente.

AT: CONTAMINACIÓN Y RESIDUOS

ACUATORIO m

Depósito de agua, especialmente reservado para la acuicultura.

AT: RECURSOS

\section{ACUICULTIVO m}

Incremento de la fauna acuática de importancia económica.

AT: RECURSOS

\section{ACUICULTURA $\mathbf{f}$}

Cultivo controlado de especies acuáticas, con el propósito de incrementar la producción y la comercialización. 
Obs.: En Iberoamérica, ACUACULTURA.

AT: AGRICULTURA

TR: PISCICULTURA

\section{ACUÍFERO m}

Formación geológica de la corteza terrestre en la que se acumulan las agua infiltradas, de afluencia o de condensación.

AT: RECURSOS

\section{AEROSOL $\mathbf{m}$}

1. Presencia de sustancias líquidas o sólidas o ambas en suspensión en un medio gaseoso, cuya velocidad de caída es prácticamente despreciable.

2. Recipiente presurizado con un mecanismo rociador incorporado que se emplea para envasar insecticidas, desodorantes, etc.

AT: CONTAMINACIÓN Y RESIDUOS

AFECTACIÓN ANTRÓPICA loc

Alteración ocasionada por la acción del hombre sobre el medio.

AT: IMPACTO AMBIENTAL

TR: AFECTACIÓN ANTROPOGÉNICA

AFECTACIÓN ANTROPOGÉNICA loc $\rightarrow$ AFECTACIÓN ANTRÓPICA

\section{AGRICIDA m}

Efecto negativo de la agricultura, como la destrucción de la tierra debido al uso de biocidas.

AT: AGRICULTURA

\section{AGRICULTURA ALTERNATIVA loc}

Sistema de técnicas agrícolas, distinto al usado normalmente, con el que se pretende lograr mejores resultados en la producción agrícola, preservando el ecosistema asociado.

AT: AGRICULTURA

AGRICULTURA BIOLÓGICA loc $\rightarrow$ AGRICULTURA ORGÁNIC

AGRICULTURA DE AUTOCONSUMO loc $\rightarrow$ AGRICULTURA ORGÁNICA

AGRICULTURA DE SUBSISTENCIA loc $\rightarrow$ AGRICULTURA ORGÁNICA

\section{AGRICULTURA ECOLÓGICA loc}

Conjunto de técnicas y métodos no químicos de atención al suelo y a la crianza de 
animales que tiene por fin la preservación de las cualidades agrícolas, la conservación de los recursos naturales y el establecimiento del equilibrio entre la naturaleza y las necesidades del hombre.

AT: AGRICULTURA

\section{AGRICULTURA ORGÁNICA loc}

Sistema de cultivo que se propone evitar el uso de agroquímicos, a través de la aplicación de la rotación de cultivos, la adición de subproductos agrícolas y el control biológico de plagas.

AT: AGRICULTURA

TR: AGRICULTURA BIOLÓGICA, AGRICULTURA DE AUTOCONSUMO, AGRICULTURA DE SUBSISTENCIA

\section{AGRICULTURA SOSTENIBLE loc}

Sistema de producción agropecuaria que permite obtener producciones estables de forma económicamente viable y socialmente aceptable, en armonía con el medio ambiente y sin comprometer las potencialidades presentes y futuras del recurso suelo.

AT: AGRICULTURA

\section{AGROECOLOGÍA f}

Empleo de conceptos y principios ecológicos en el estudio, diseño y control de los sistemas agrícolas.

AT: AGRICULTURA

\section{AGROECOSISTEMA m}

Ecosistema correspondiente al $\underline{\text { uso }}$ agropecuario del espacio.

AT: AGRICULTURA

TR: AGROPAISAJE

AGROPAISAJE $m \rightarrow$ AGROECOSISTEMA 